ARTICLE

Received 7 Jun 2016 | Accepted 14 Oct 2016 | Published 30 Nov 2016

DOI: $10.1038 /$ ncomms13638

OPEN

\title{
Platinum single-atom and cluster catalysis of the hydrogen evolution reaction
}

\author{
Niancai Cheng ${ }^{1, \star}$, Samantha Stambula ${ }^{2, \star}$, Da Wang ${ }^{3, \star}$, Mohammad Norouzi Banis ${ }^{1}$, Jian Liu $^{1}$, Adam Riese ${ }^{1}$, \\ Biwei Xiao ${ }^{1}$, Ruying Li ${ }^{1}$, Tsun-Kong Sham ${ }^{4}$, Li-Min Liu ${ }^{3}$, Gianluigi A. Botton ${ }^{2,5,6}$ \& Xueliang Sun ${ }^{1}$
}

Platinum-based catalysts have been considered the most effective electrocatalysts for the hydrogen evolution reaction in water splitting. However, platinum utilization in these electrocatalysts is extremely low, as the active sites are only located on the surface of the catalyst particles. Downsizing catalyst nanoparticles to single atoms is highly desirable to maximize their efficiency by utilizing nearly all platinum atoms. Here we report on a practical synthesis method to produce isolated single platinum atoms and clusters using the atomic layer deposition technique. The single platinum atom catalysts are investigated for the hydrogen evolution reaction, where they exhibit significantly enhanced catalytic activity (up to 37 times) and high stability in comparison with the state-of-the-art commercial platinum/carbon catalysts. The X-ray absorption fine structure and density functional theory analyses indicate that the partially unoccupied density of states of the platinum atoms' $5 d$ orbitals on the nitrogen-doped graphene are responsible for the excellent performance.

\footnotetext{
${ }^{1}$ Department of Mechanical and Materials Engineering, University of Western Ontario, London, Ontario, Canada N6A 5B9. ${ }^{2}$ Department of Materials Science and Engineering, McMaster University, Hamilton, Ontario, Canada L8S 4L8. ${ }^{3}$ Beijing Computational Science Research Center, Beijing 100193, China. ${ }^{4}$ Department of Chemistry, University of Western Ontario, London, Ontario, Canada N6A 5B7. ${ }^{5}$ Brockhouse Institute for Materials Research, McMaster University, Hamilton, Ontario, Canada L9S 4M1. ${ }^{6}$ Canadian Centre for Electron Microscopy, McMaster University, Hamilton, Ontario, Canada L8S 4M1.

* These authors contributed equally to this work. Correspondence and requests for materials should be addressed to L.-M.L. (email: limin.liu@csrc.ac.cn) or to G.A.B. (email: gbotton@mcmaster.ca) or to X.S. (email: xsun@eng.uwo.ca).
} 
S ecuring renewable and reliable sources of clean energy is one of the world's foremost challenges. Addressing this challenge is not only critical for the global economy but will also aid in the mitigation of environmental and health hazards caused by fossil fuels ${ }^{1}$. Hydrogen is the cleanest fuel available and is believed to be one of the most promising energy sources of the twenty-first century ${ }^{2,3}$. However, the majority of the hydrogen produced today is derived from steam-reformed methane, which is sourced from fossil reserves and produces a substantial amount of $\mathrm{CO}_{2}$ (ref. 4). The production of hydrogen from water electrolysis is a promising alternative to the current $\mathrm{CO}_{2}$-emitting fossil fuel-based energy systems ${ }^{5,6}$.

Platinum (Pt)-based catalysts are generally considered to be the most effective electrocatalysts for the hydrogen evolution reaction (HER $)^{5,7}$. Unfortunately, $\mathrm{Pt}$ is expensive and scarce, limiting the commercial potential for such catalysts. The development of active, stable and inexpensive electrocatalysts for water splitting is a key step in the realization of a hydrogen economy, which is based on the use of molecular hydrogen for energy storage.
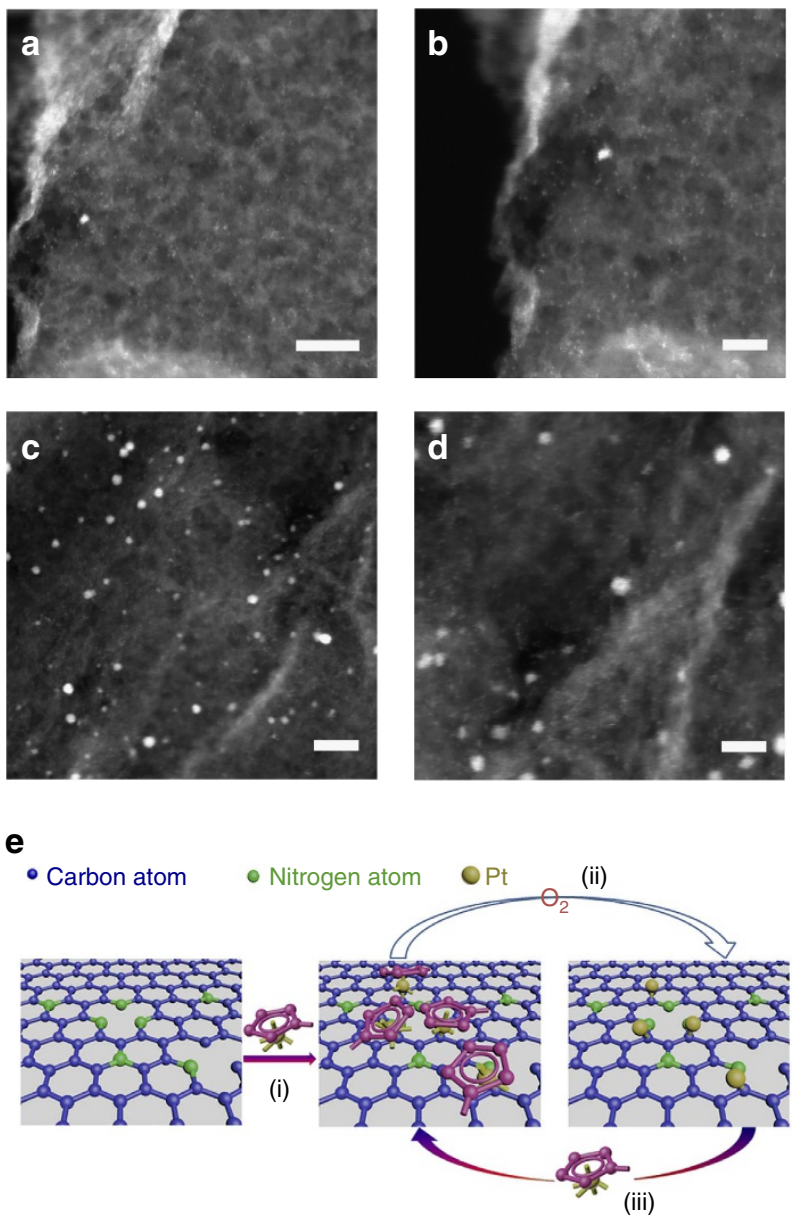

Figure 1 | ADF STEM images and schematic illustration of the Pt ALD mechanism on NGNs. ADF STEM images of ALDPt/NGNs samples with (a,b) 50 and (c,d) 100 ALD cycles. Scale bars, $10 \mathrm{~nm}(\mathbf{a}, \mathbf{c}) ; 5 \mathrm{~nm}(\mathbf{b}, \mathbf{d})$. (e) Schematic illustration of the Pt ALD mechanism on NGNs. The ALD process includes the following: the Pt precursor $\left(\mathrm{MeCpPtMe}_{3}\right)$ first reacts with the $\mathrm{N}$-dopant sites in the NGNs (i). During the following $\mathrm{O}_{2}$ exposure, the Pt precursor on the NGNs is completely oxidized to $\mathrm{CO}_{2}$ and $\mathrm{H}_{2} \mathrm{O}$, creating a Pt containing monolayer (ii). These two processes ( $\mathrm{i}$ and ii) form a complete ALD cycle. During process (ii), a new layer of adsorbed oxygen forms on the platinum surface, which provides functional groups for the next ALD cycle process (iii).
Significant effort has been devoted to the search of non-preciousmetal-based HER catalysts, including sulfide-based materials ${ }^{8-11}$, and $\mathrm{C}_{3} \mathrm{~N}_{4}$ (refs 12-14). Although these candidate materials show promising activities for the HER, the activities of these catalysts in their present form are insufficient for industrial applications ${ }^{15}$.

To overcome the challenges associated with the Pt HER catalysts and to drive the cost of $\mathrm{H}_{2}$ production from water electrolysis down, it is very important to markedly decrease the $\mathrm{Pt}$ loading and increase the $\mathrm{Pt}$ utilization efficiency. Currently, supported Pt nanoparticles (NPs) are typically used to promote $\mathrm{Pt}$ activity towards the HER. Unfortunately, the geometry of the NPs limit the majority of the $\mathrm{Pt}$ atoms to the particle core, deeming them ineffective, as only surface atoms are involved in the electrochemical reaction ${ }^{16}$. Reducing the size of the Pt NPs to clusters or even single atoms could significantly decrease the noble metal usage and increase their catalytic activity, which is highly desirable to enhance the Pt utilization and decrease the cost of the electrocatalysts ${ }^{17}$. It has been shown that single $\mathrm{Pt}$ atoms dispersed on an $\mathrm{FeO}_{x}$ surface have a higher catalytic activity for $\mathrm{CO}$ oxidation compared with the corresponding $\mathrm{Pt}$ $\mathrm{NPs}^{18}$. Moreover, the single-atom catalysts also exhibited a significantly improved catalytic activity towards methanol oxidation, up to 10 times greater than the state-of-the-art commercial carbon-supported $\mathrm{Pt}(\mathrm{Pt} / \mathrm{C})$ catalysts ${ }^{19}$.

Controlled and large-scale synthesis of stable single atoms and clusters remains a considerable challenge due to the natural tendency for metal atoms to diffuse and agglomerate, resulting in the formation of larger particles ${ }^{20,21}$. In practical applications, it is required that the single atoms not only have a high activity but also exhibit a satisfactory stability ${ }^{17,22,23}$. Moreover, it is also desired to produce a high density of single atoms to meet the practical applications. Consequently, an ideal single-atom catalyst must have a high activity, a high stability and a high density. Thus, we need to discover an effective means to synthesize this ideal single-atom catalyst. In this paper, the atomic layer deposition (ALD) technique was utilized, as it has been proven to be a powerful tool for large-scale synthesis of stable singleatom and cluster catalysts ${ }^{19,24}$. ALD has the ability to precisely control the size and distribution of particles on a substrate by using sequential and self-limiting surface reactions ${ }^{25-27}$.

In this work, we fabricate single platinum atoms and clusters supported on nitrogen-doped graphene nanosheets (NGNs) for the HER using the ALD technique, resulting in the utilization of nearly all the Pt atoms. The size and density of the Pt catalysts on the NGNs are precisely controlled by simply adjusting the number of ALD cycles. The Pt atoms and clusters on the NGNs show much greater activity for the HER in comparison with conventional Pt NP catalysts.

\section{Results}

Electron microscopy characterization. The morphology of the ALD Pt on NGNs with 50 and 100 cycles (denoted hereafter as ALD50Pt/NGNs and ALD100Pt/NGNs, respectively) were characterized by annular dark field (ADF) imaging with aberrationcorrected scanning transmission electron microscopy (STEM). The high spatial resolution allowed for the precise determination of the size and distribution of the individual metal atoms, thus providing local structural information about the metal species on the NGN supports ${ }^{24,28,29}$. It can be clearly observed in Fig. 1a,b that the numerous individual $\mathrm{Pt}$ atoms (bright spots), as well as very small Pt clusters are uniformly dispersed on the NGNs' surface for the ALD50Pt/NGNs catalysts. Through examination of multiple NGNs, small NPs were also detected on this sample (Supplementary Fig. 1a). After 100 ALD cycles many single Pt atoms and small clusters were still present, yet it appears as 
though some Pt clusters have grown to form NPs at a larger quantity than observed for the 50 ALD cycles (Fig. 1c,d and Supplementary Fig. 1b). These findings suggest that ALD is a suitable technique for preparing single atoms/clusters on nitrogen-doped graphene supports. As shown in Fig. 1e, during the ALD process, the Pt precursor $\left(\mathrm{MeCpPtMe}_{3}\right)$ first reacts with the NGNs as influenced by the N-dopant. The chemical bonding between the Pt precursor and NGNs ensures a strong interaction between the deposited material and the support ${ }^{30}$. The Pt loading after ALD was confirmed using inductively coupled plasmaatomic emission spectroscopy, in which a loading of 2.1 and $7.6 \mathrm{wt} \%$ was obtained for the 50 and 100 ALD cycled samples, respectively.

Catalytic performance and stability. The HER activity of the ALDPt/NGNs with 50 and 100 cycles were measured in comparison with commercial $\mathrm{Pt} / \mathrm{C}$ catalysts by conducting linear sweep voltammetry measurements in $0.5 \mathrm{M} \mathrm{H}_{2} \mathrm{SO}_{4}$ at room temperature. The NGNs without Pt catalysts exhibited a poor HER activity (Fig. 2a), which is consistent with previous studies ${ }^{12}$. As shown in Fig. 2a, both ALDPt/NGN and Pt/C catalysts exhibited excellent catalytic activities towards the HER, with negligible overpotentials. Importantly, the ALDPt/NGN catalysts exhibited much higher HER activities than that of the commercial $\mathrm{Pt} / \mathrm{C}$ catalysts (Fig. 2a). It was observed that the HER catalytic activity of the ALDPt/NGNs decreased with an increased number of ALD cycles. This is likely attributed to the increased formation of clusters or NPs in the sample with 100 ALD cycles. Supplementary Fig. 2 showed consistent results with previous studies, as the $\mathrm{Pt} / \mathrm{C}$ catalyst achieved a Tafel slope of $31 \mathrm{mV} \mathrm{dec}^{-1}$ (ref. 31). Following the same measurement parameters, a smaller Tafel slope than the $\mathrm{Pt} / \mathrm{C}$ catalysts was achieved for the ALDPt/NGNs catalysts at $29 \mathrm{mV} \mathrm{dec}^{-1}$. The specific activity for each catalyst was calculated from the polarization curves by normalizing the current with the geometric area of the electrode. As shown in Supplementary Fig. 3, the HER activities for the ALD50Pt/NGNs, ALD100Pt/ NGNs and Pt/C catalysts are $16,12.9$ and $8.2 \mathrm{~mA} \mathrm{~cm}^{-2}$, respectively, at the overpotential of $0.05 \mathrm{~V}$. Furthermore, normalized to the Pt loading (Fig. 2b), the mass activity of the HER for the ALD50Pt/NGNs catalysts at the overpotential of $0.05 \mathrm{~V}$ was $10.1 \mathrm{~A} \mathrm{mg}^{-1}$. Remarkably, the mass activity of the ALD50Pt/NGNs catalyst was 7.8 times greater than the ALD100Pt/NGNs catalyst $\left(2.12 \mathrm{~A} \mathrm{mg}^{-1}\right)$ and 37.4 times greater than the $\mathrm{Pt} / \mathrm{C}$ catalyst $\left(0.27 \mathrm{~A} \mathrm{mg}^{-1}\right)$. These findings suggest that the single $\mathrm{Pt}$ atoms and clusters can significantly increase the $\mathrm{Pt}$ utilization activity in comparison to their NP counterparts ${ }^{18,32}$, with the additional benefit of decreasing the cost of the catalyst for the HER.

The long-term stability of the ALDPt/NGNs and Pt/C catalysts were examined by extended electrolysis at fixed potentials. Supplementary Fig. 4 shows that the ALDPt/NGNs catalysts appear stable at $0.04 \mathrm{~V}$ versus reversible hydrogen electrode (RHE), while the current density of the $\mathrm{Pt} / \mathrm{C}$ catalysts degraded with time at the same operating conditions. The lower stability of the $\mathrm{Pt} / \mathrm{C}$ catalysts may be due to a weak interaction between the supported Pt particles and the $\mathrm{C}$ substrate $\mathrm{P}^{33}$, resulting in the detachment and/or agglomeration of the Pt NPs. Accelerated degradation tests (ADTs) were also adopted to evaluate the durability of the Pt atom/cluster catalysts for the HER activity. As exhibited in Fig. 2c, the ALD50Pt/NGNs catalysts' polarization curve after 1,000 cycles retained a similar performance to the initial test, resulting in a loss of only $4 \%$ of its initial current density at an overpotential of $0.05 \mathrm{~V}$ (Supplementary Fig. 5). The significant stability of the ALD50Pt/NGNs catalysts can be observed when comparing its performance with the ALD100Pt/
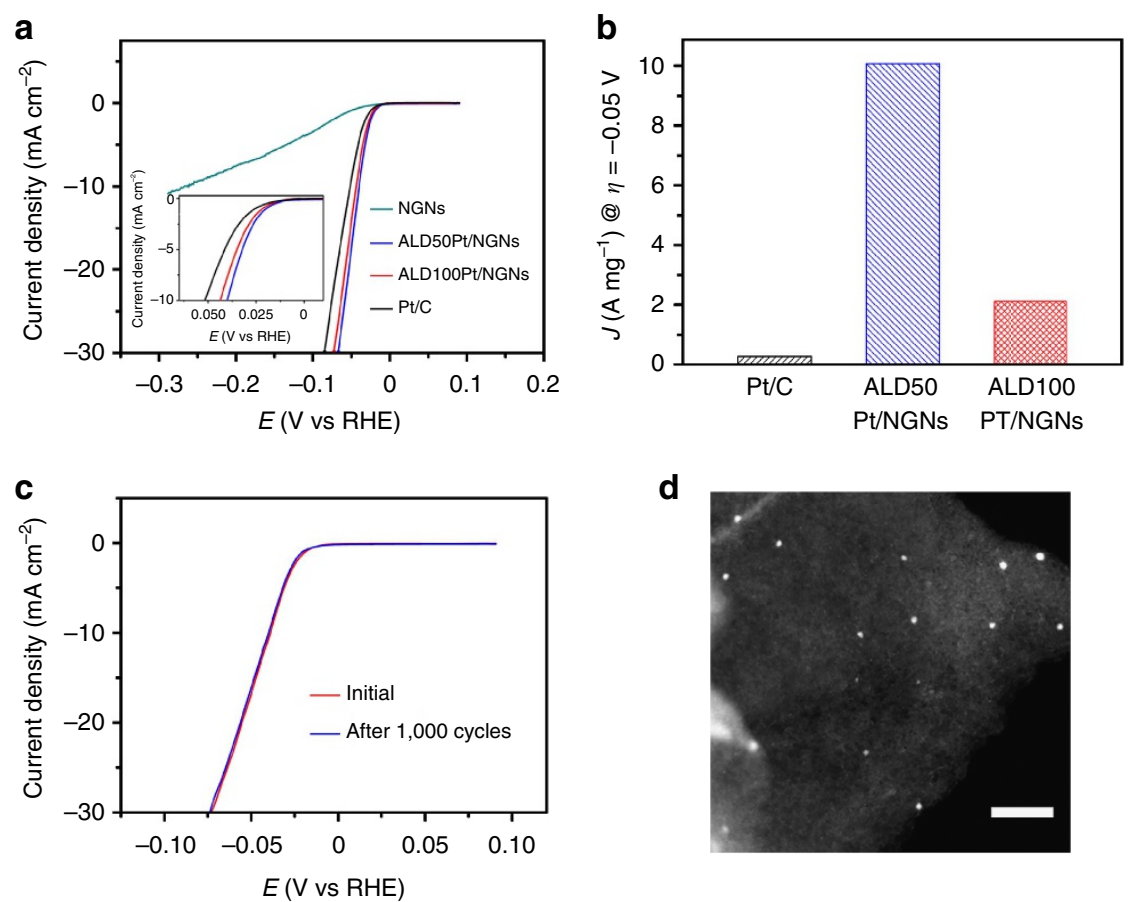

Figure 2 | Electrocatalytic properties. (a) The HER polarization curves for ALDPt/NGNs and Pt/C catalysts were acquired by linear sweep voltammetry with a scan rate of $2 \mathrm{mVs}^{-1}$ in $0.5 \mathrm{M} \mathrm{H}_{2} \mathrm{SO}_{4}$ at room temperature. $\mathrm{N}_{2}$ was purged before the measurements. The inset shows the enlarged curves at the onset potential region of the HER for the different catalysts. (b) Mass activity at $0.05 \mathrm{~V}$ (versus RHE) of the ALDPt/NGNs and the Pt/C catalysts for the HER. (c) Durability measurement of the ALD50Pt/NGNs. The polarization curves were recorded initially and after 1,000 cyclic voltammetry sweeps between +0.4 and $-0.15 \mathrm{~V}$ (versus RHE) at $100 \mathrm{mVs}^{-1}$ in $0.5 \mathrm{M} \mathrm{H}_{2} \mathrm{SO}_{4}$ at a scan rate of $2 \mathrm{mVs}^{-1}$. (d) ADF STEM images of ALD50Pt/NGNs samples after ADT; scale bar, $20 \mathrm{~nm}$. 
NGNs catalysts ( 10\% loss) and the Pt/C catalysts (19\% loss) under the same measurement conditions (Supplementary Figs 5 and 6).

STEM images acquired from the ALDPt/NGNs after the ADTs (Fig. 2d and Supplementary Fig. 7) showed that there was only a slight increase in the Pt size with no obvious aggregation. This further supports the excellent stability observed in the activity from the ALDPt/NGNs catalysts during the ADTs for the HER. In contrast, according to high-resolution transmission electron microscope images, the $\mathrm{Pt} / \mathrm{C}$ catalysts (Supplementary Fig. 8) coalesced into larger particles (marked with white circles in Supplementary Fig. 8b) with the average size of Pt NPs increasing from 4.2 to $5.5 \mathrm{~nm}$ after the ADT. The growth of the NPs may be caused by Pt migration due to weak interactions between the catalyst and the support ${ }^{34,35}$. As shown in Supplementary Fig. 9, the negative potentials of a HER cathode are generally not conducive for electro-oxidation of the support material. In addition, $\mathrm{Pt}$ is one of the most stable electrocatalyst materials $^{36,37}$, and $\mathrm{Pt}$ oxidation/dissolution is typically not observed at potentials $<0.85 \mathrm{~V}$ versus RHE in acidic conditions, thus the $\mathrm{Pt}$ and the $\mathrm{C}$ supports are stable under HER conditions. This suggests that the higher stability of the $\mathrm{Pt}$ atoms/clusters observed on the ALDPt/NGNs samples could be ascribed to the stronger interactions between the $\mathrm{Pt}$ and the NGNs supports compared to the Pt/C catalysts.

X-ray absorption spectroscopy studies. X-ray absorption spectroscopy was used to study the local electronic structure of the $\mathrm{Pt}$ catalysts and their interaction with the support material ${ }^{38,39}$. The normalized X-ray absorption near edge structure (XANES) spectra for both the $\mathrm{Pt}_{3_{3}}$ and $\mathrm{L}_{2}$-edges of the ALDPt/NGNs and $\mathrm{Pt} / \mathrm{C}$ catalysts are shown in Fig. 3 with comparison to a standard Pt foil. It can be seen in Fig. 3 that the threshold energy $\left(E_{0}\right)$ and the maximum energy $\left(E_{\text {peak }}\right)$ of the $\mathrm{Pt} \mathrm{L}_{3}$-edge for the ALDPt/NGNs are similar to those of the corresponding metal foil, thus confirming the metallic nature of the Pt atoms and clusters on the ALDPt/NGNs samples. Furthermore, detailed examination of the spectra was conducted by qualitative and quantitative analysis of the $\mathrm{Pt} \mathrm{L}_{2}$ and $\mathrm{L}_{3}$ white line $(\mathrm{WL})$ edges. It has been shown that the area under the WL of the $\mathrm{L}_{2,3}$-edge of the Pt metal is directly related to the unoccupied density of states of the Pt $5 d$ orbitals. This in turn has been used to correlate the catalytic activity of Pt-based electrocatalysts to changes in their local electronic structure. Close examination reveals that the intensity of the $\mathrm{Pt} \mathrm{L}_{3} \mathrm{WL}$ exhibits small differences for the ALDPt/NGNs and the Pt/C catalysts. The magnitude of the $\mathrm{Pt}$ WL intensity at the $\mathrm{Pt}_{\mathrm{L}_{3}}$-edge appears to increase in the order of Pt foil $<$ Pt $/ \mathrm{C}<$ ALD100Pt/NGNs $<$ ALD50Pt/NGNs (Fig. 3a). In contrast, the corresponding $\mathrm{L}_{2}$-edge $\mathrm{WL}$ exhibits considerably more variation among the samples and a higher sensitivity compared with that of the $\mathrm{Pt} \mathrm{L}_{3}$-edge, resulting in a different trend for the ALDPt/NGNs and the Pt/C materials. The order of increasing intensity of the $\mathrm{WL}$ in the $\mathrm{Pt} \mathrm{L}_{2}$-edge is as follows: $\mathrm{Pt}$ foil $<$ ALD100Pt/NGNs $\leq \mathrm{Pt} / \mathrm{C}<\mathrm{ALD} 50 \mathrm{Pt} / \mathrm{NGNs}$ (Fig. 3b). This observation clearly confirms that for $5 d$ noble metal states, the $5 d_{5 / 2}$ and $5 d_{3 / 2}$, demonstrate subtle but different chemical sensitivity due to the large spin-orbit coupling of the $\mathrm{Pt} 5 d$ orbitals, and that both the $\mathrm{L}_{3^{-}}$and $\mathrm{L}_{2}$-edge WLs should be used together to address the chemistry of the material ${ }^{19}$.

To fully understand the effect of the unoccupied densities of $5 d$ states of the Pt catalysts, quantitative WL intensity analysis has been conducted on the basis of a reported method to determine the occupancy of the $5 d$ states in each sample ${ }^{38,40,41}$ (see details in Methods). The $\mathrm{Pt} \mathrm{L}_{3}$ - and $\mathrm{Pt} \mathrm{L}_{2}$-edge threshold and $\mathrm{WL}$ parameters were summarized in Table 1 . The results indicate that

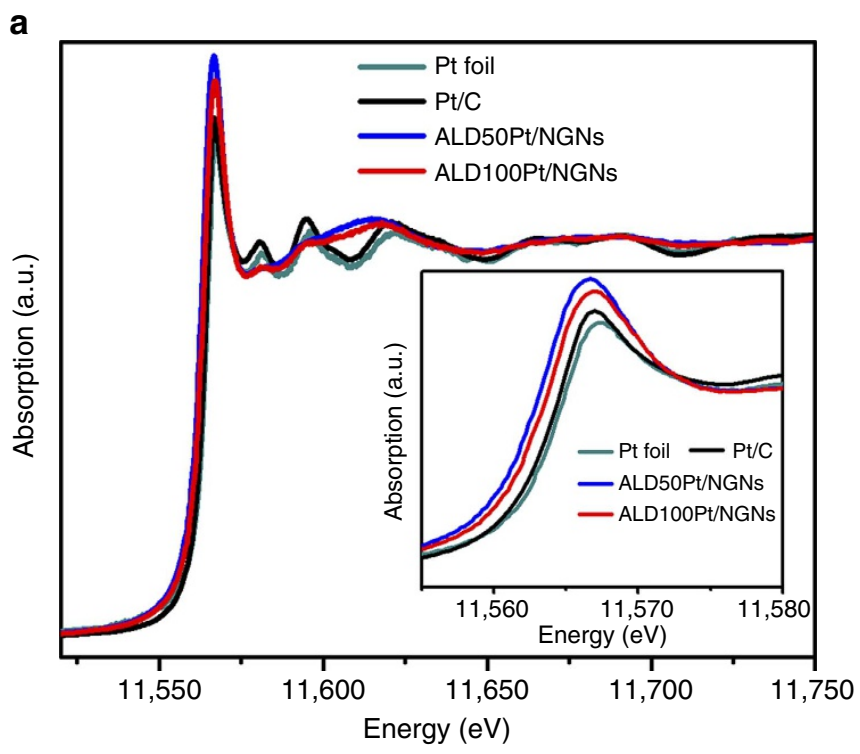

b

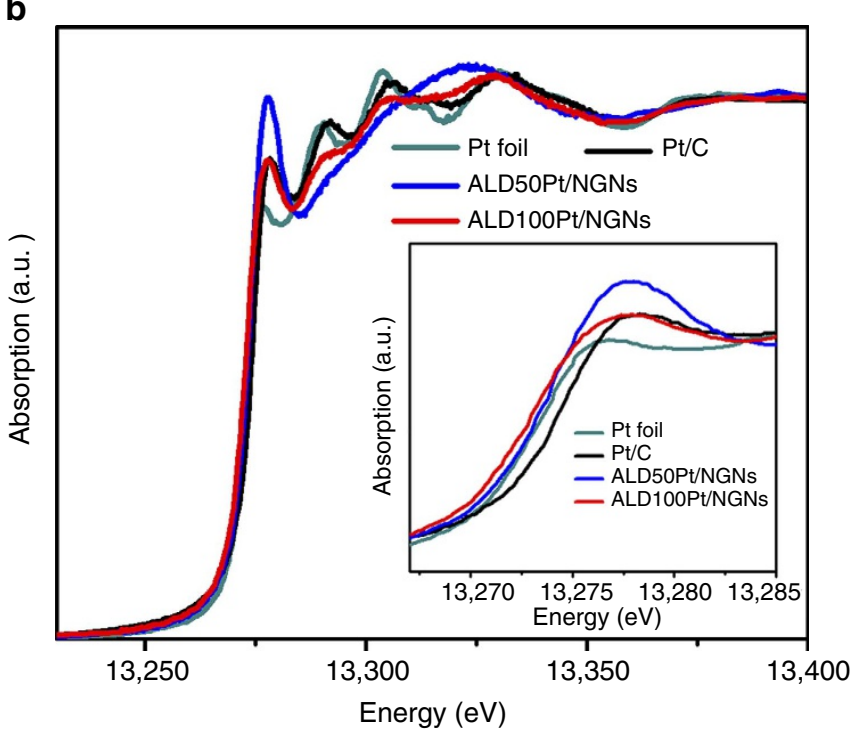

Figure 3 | X-ray absorption studies. (a) The normalized XANES spectra at the Pt $\mathrm{L}_{3}$-edge of the ALDPt/NGNs, Pt/C catalysts and Pt foil. The inset shows the enlarged spectra at the $\mathrm{Pt} \mathrm{L}_{3}$-edge. (b) The normalized XANES spectra at the Pt $\mathrm{L}_{2}$-edge of ALDPt/NGNs, Pt/C catalysts and Pt foil. The inset shows the enlarged spectra at the $P t L_{2}$-edge $\mathrm{WL}$.

the ALD50Pt/NGNs catalysts have the highest total unoccupied density of states of Pt $5 d$ character, while the $\mathrm{Pt} / \mathrm{C}$ sample has the lowest. It has been demonstrated in literature that the vacant $d$-orbitals of individual atoms play a vital role in the activity of catalysts and account for the excellent catalytic activity of single-atom catalysts ${ }^{18,42}$.

Furthermore, to study the local atomic structure of Pt using Xray absorption spectra (XAS), the extended X-ray absorption fine structure (EXAFS) region of the X-ray absorption spectra was studied. The Fourier transforms of the EXAFS region plotted in Supplementary Fig. 10 shows several main peaks. The peak at 2.6 $\AA$ is associated with the Pt-Pt peak, which is significant in the $\mathrm{Pt}$ foil spectra. This peak shifts towards lower values in the $\mathrm{Pt} / \mathrm{C}$ samples $(2.5 \AA)$, and is significantly dampened and shifted to higher values $(2.7 \AA)$ in the ALD-deposited samples. This is consistent with previously reported data on ALD-deposited $\mathrm{Pt}$ nanostructures ${ }^{19}$. However, as expected, due to the higher $\mathrm{Pt}$ 


\begin{tabular}{|c|c|c|c|c|c|c|c|c|c|c|}
\hline \multirow[t]{2}{*}{ Sample } & \multicolumn{4}{|c|}{ Pt $\mathrm{L}_{3}$-edge WL } & \multicolumn{4}{|c|}{ Pt $L_{2}$-edge WL } & \multirow[b]{2}{*}{$h_{5 / 2}$} & \multirow[b]{2}{*}{$h_{3 / 2}$} \\
\hline & $E_{0}(\mathrm{eV})$ & $E_{\text {peak }}(e V)$ & $\Gamma(\mathrm{eV})$ & $\Delta \boldsymbol{A}_{\mathbf{3}}$ & $E_{0}(\mathrm{eV})$ & $E_{\text {peak }}(\mathrm{eV})$ & $\Gamma(\mathrm{eV})$ & $\Delta \boldsymbol{A}_{2}$ & & \\
\hline Pt foil & 11,564 & $11,567.3$ & 6.4 & 5.61213 & 13,273 & $13,275.8$ & 6.5 & 3.38168 & 0.511733 & 0.157245409 \\
\hline $\mathrm{Pt} / \mathrm{C}$ & $11,563.98$ & $11,567.5$ & 7.3 & 6.18031 & 13,273 & $13,276.7$ & 6.2 & 4.43669 & 0.5580197 & 0.206302528 \\
\hline ALD50Pt/NGNs & $11,563.94$ & $11,567.4$ & 8.5 & 7.72907 & $13,272.98$ & $13,276.8$ & 8.6 & 4.92513 & 0.7026908 & 0.229014596 \\
\hline ALD100Pt/NGNs & $11,563.98$ & $11,567.4$ & 8 & 7.10892 & 13,273 & $13,276.7$ & 7.8 & 4.63292 & 0.6455094 & 0.215427066 \\
\hline
\end{tabular}

content of the ALD100Pt/NGNs sample, the intensity of the PtPt peak in comparison with the ALD50Pt/NGNs sample is stronger, which confirms the presence of larger clusters and the higher loading observed in the ALD100Pt/NGNs samples by ADF imaging and inductively coupled plasma-atomic emission spectroscopy results. The peaks observed around $1.7 \AA$ in the ALD-deposited samples can be related to $\mathrm{Pt}-\mathrm{O}$ or $\mathrm{Pt}-\mathrm{C}$ bonds, but individual bond lengths are not distinguishable due to a similar backscattering phase. The significant intensity of Pt-O or $\mathrm{Pt}-\mathrm{C}$ bonds and considerable deviation of the Pt-Pt bond of the ALD samples compared with the Pt foil indicates the presence of single Pt atoms in these samples.

\section{Discussion}

It has been demonstrated that a strong interaction between the deposited metal and the support material plays a vital role in the stabilization of supported catalysts ${ }^{43}$. Despite the controlled deposition process during ALD, atomic diffusion and agglomeration are still possible and probable, if a weak interaction exists between the atoms and the support, thus resulting in the formation of large particles. This suggests the importance of the support selection when striving to prepare stable atom catalysts. It has been reported in the literature that doping the graphene lattice with $\mathrm{N}$ can enhance the $\mathrm{Pt}-\mathrm{C}$ support interaction energy, resulting in highly stable Pt catalysts ${ }^{44-46}$. This enhanced binding energy from the incorporation of $\mathrm{N}$-dopants in the graphene lattice has been attributed to creating preferred nucleation sites for metals and metal oxides $^{4}$. In addition, it was determined in one of our previous experiments that the $\mathrm{Pt}$ atoms and clusters favour deposition at edge locations on NGNs, thus stabilizing the creation of Pt atoms and clusters without the formation of $\mathrm{NPs}^{24}$. To further examine the effects of the $\mathrm{N}$-dopants on the stability of the Pt atoms and clusters observed in Fig. 1 and to expand on the understanding of the N-dopant's contribution to the HER, we have prepared ALD-deposited Pt on graphene nanosheets (GNs) for comparison. Supplementary Fig. 11 exhibits low- and highmagnification ADF images of ALD50Pt/GNs, in which there is a wide distribution of $\mathrm{Pt}$ sizes from atoms and clusters to larger NPs. It can be suggested that the formation of larger particles on the GNs during the ALD procedure can be attributed to the weaker interaction between the Pt and the graphene support in contrast to the $\mathrm{N}$-doped graphene support. Furthermore, the HER activity was evaluated for the ALD50Pt/GNs sample using linear sweep voltammetry with a scan rate of $2 \mathrm{mV} \mathrm{s}^{-1}$ in $0.5 \mathrm{M}$ $\mathrm{H}_{2} \mathrm{SO}_{4}$, which revealed a lower mass and specific activity in comparison with the ALD50Pt/NGNs sample (Supplementary Fig. 12). The stability of the Pt catalysts on the GNs was also confirmed using $\mathrm{ADT}$ tests. It was determined that the ALD50Pt/GNs sample lost $24 \%$ of its initial HER activity (Supplementary Fig. 13), while as previously reported, the ALD50Pt/NGNs only decreased its activity by $4 \%$. Following the ADT test, the ALD50Pt/GNs sample was examined using $\mathrm{ADF}$ imaging, where an increased frequency of larger clusters and NPs was observed (Supplementary Figs 11 and 13). This suggests that the increased Pt particle size on the ALD50Pt/GNs sample from the ADT tests is responsible for the reduced HER activity after cycling. It can be suggested that the increased Pt particle size with cycling on the GNs is likely originating from a weaker adsorption energy, thus leading to a decreased stability of the Pt atoms, clusters and NPs, allowing them to become susceptible to degradation mechanisms ${ }^{48}$. Ultimately, this supports the argument that the strength of the interaction between the Pt catalysts and support increases on NGNs in comparison with GNs, which accounts for the increased stability and activity after ADT cycling.

To understand the stabilization mechanism of Pt atoms on $\mathrm{N}$-doped graphene, we applied density functional theory (DFT) calculations. The DFT calculations have been carried out using a graphene $(5 \times 5 \times 1)$ supercell containing $48 \mathrm{C}$ atoms and $1 \mathrm{~N}$ atom to identify the distribution of single Pt atoms on the NGNs. All inequivalent Pt-adsorption configurations around the $\mathrm{N}$ atom have been considered, and the most stable configurations are shown in Supplementary Fig. 14. It can be seen that in site III, $\mathrm{Pt}$ is located closest to the N atom, while in site I, II, IX, X and XI the Pt atom is situated further away from the N-dopant. To determine the most stable adsorption site for the Pt atom, the adsorption energies $\left(E_{\mathrm{a}}\right)$ for each site in Supplementary Fig. 14 were calculated by the following equation:

$$
E_{\mathrm{a}}=\left(E_{\mathrm{NGNs}}+n E_{\mathrm{Pt}}-E_{\mathrm{NGNs}}+n \mathrm{Pt}\right) / n
$$

where $E_{\mathrm{Pt}}$ is the energy of an isolated Pt atom, $E_{\mathrm{NGNs}}$ is the total energy of the $\mathrm{N}$-doped graphene and $E_{\mathrm{NGNs}+n \mathrm{Pt}}$ is the total energy of the $\mathrm{N}$-doped graphene with $n$ adsorbed Pt atoms, respectively. A positive $E_{\mathrm{a}}$ indicates the successful adsorption of the $\mathrm{Pt}$ atoms during the $\mathrm{N}$-doped graphene.

As shown in Supplementary Table 1, the Pt atom prefers to directly bond to the N-dopant, as demonstrated by the significantly larger calculated adsorption energy of $5.171 \mathrm{eV}$ for a Pt atom in site III in comparison with the other adsorption sites. Moreover, the calculated Bader charge shows that $0.257 e$ is transferred from the Pt to the $\mathrm{N}$ atom in the $\mathrm{N}$-doped graphene substrate when the system is in its most stable configuration (site III), confirming the relatively large Pt adsorption energy at this site. These results clearly suggest that the Pt prefers to adsorb to the $\mathrm{N}$-dopant sites on Pt deposition.

To further examine the distribution of the Pt atoms on the $\mathrm{N}$-doped graphene and their propensity to agglomerate, the energy difference between an isolated Pt atom and a Pt cluster configuration, $\Delta E_{\mathrm{d}}$, was calculated, in which the total energy of the isolated configuration was used as a reference energy. In this scheme, a relatively large positive value for $\Delta E_{\mathrm{d}}$ indicates that Pt atoms energetically favour the single-atom form and will tend to avoid clustering. For comparison of substrates, the production of various Pt cluster configurations on pristine graphene was also examined. As shown in Supplementary Fig. 15 and Supplementary Table 2, it is more favourable for the Pt atoms to be isolated $\left(\Delta E_{\mathrm{d}}=+1.145 \mathrm{eV}\right)$ on the $\mathrm{N}$-doped graphene, while the Pt atoms prefer to cluster on the pristine graphene $\left(\Delta E_{\mathrm{d}}=-1.357 \mathrm{eV}\right)$. This fully supports the experimental 
observations of the increased size of the Pt clusters and NPs on the graphene substrate in comparison with the $\mathrm{N}$-doped graphene.

A Bader charge analysis (Supplementary Table 2) has also been performed on the adsorption models for the pristine and $\mathrm{N}$-doped graphene to understand the formation of bonds through charge transfer. A charge transfer (about $0.25 e$ ) from the Pt atom to the support occurs on the $\mathrm{N}$-doped graphene for the single $\mathrm{Pt}$ atom case, while almost no charge transfer exists between the $\mathrm{Pt}$ atom and the pristine graphene. When two $\mathrm{Pt}$ atoms form a dimer on the $\mathrm{N}$-doped graphene, one $\mathrm{Pt}$ atom $\left(\mathrm{Pt}^{1}\right)$ interacts with the graphene support, whilst the other $\left(\mathrm{Pt}^{2}\right)$ atom sits above and bonds directly to $\mathrm{Pt}^{1}$. Meanwhile, $\mathrm{Pt}^{1}$ loses $0.521 e$ to $\mathrm{Pt}^{2}$, and $\mathrm{Pt}^{2}$ gains $0.389 e$ due to the strong bonding between $\mathrm{Pt}^{1}-\mathrm{Pt}^{2}$. In this cluster configuration, the surrounding $\mathrm{N}$ and $\mathrm{C}$ atoms acquire the remaining $0.132 e$, which is less than the single-atom case. This suggests that the two $\mathrm{Pt}$ atoms result in an increased electron transfer to the substrate when they exist in isolation as compared with forming a dimer; therefore, the stabilization of single atoms is favoured. On the other hand, the Pt dimer adsorbed on the pristine graphene leads to an electron transfer of $0.193 e$ from $\mathrm{Pt}^{1}$ $(0.087 e)$ and the graphene support to $\mathrm{Pt}^{2}$, whereas very little electron transfer occurs during the formation of the single isolated atoms on the pristine graphene. Thus, the dimer results in a system of increased stability. It can be concluded from the Bader charge and the $\Delta E_{\mathrm{d}}$ that isolated atoms are the preferred form of $\mathrm{Pt}$ adsorption on the $\mathrm{N}$-doped graphene support, while pristine graphene will favour the formation of Pt clusters.

The chemical bonding of Pt with the $\mathrm{N}$-doped graphene has also led to unique electronic properties of single $\mathrm{Pt}$ atoms with respect to Pt NPs, due to the charge transfer required for bond formation. The single metal atoms still carry a charge after adsorption onto the $\mathrm{N}$-doped graphene substrate, which can be verified by various spectral measurements and computational modelling of the catalysts ${ }^{18,49-51}$. In our study, it was found that the discrete $5 d$-orbitals of the single Pt atoms are mixed with the $\mathrm{N}-2 p$ orbitals around the Fermi level (Fig. 4). The calculated Bader charges (Table 2) show that the single Pt atoms are positively charged, where the $\mathrm{N}$ atom obtains the electron. In this case, the single $\mathrm{Pt}$ atoms on the $\mathrm{N}$-doped graphene contain more unoccupied $5 d$ densities of states. On $\mathrm{H}$ chemisorption (Fig. 4b), the $5 d$ orbitals of the $\mathrm{Pt}$ atoms interact strongly with the $1 s$ orbital of the $\mathrm{H}$ atoms, leading to electron pairing and hydride formation. In addition, more Pt $(5 d)$ states are found above the Fermi level, which is consistent with the calculated charge transfer from the $\mathrm{Pt}$ atoms to the $\mathrm{H}$ atoms. To fully understand the unique electronic properties of the single Pt atom catalysts for the HER, Pt clusters were also examined. As shown in Supplementary Fig. 16, the electronic properties for $\mathrm{H}$ adsorption on $\mathrm{Pt}$ clusters was investigated using a typical cluster of $\mathrm{Pt}_{44}$ (ref. 52). On the basis of the partial density of states and Bader charge analysis of both $\mathrm{H}$ adsorption on $\mathrm{Pt}_{44}$ and on the single $\mathrm{Pt}$ atoms/NGNs system (Table 2, Fig. 4 and Supplementary Fig. 16) it was found that the electron transfer from each surface $\mathrm{Pt}$ atom of $\mathrm{Pt}_{44}$ to $\mathrm{H}$ is $<0.1 \mathrm{e}$, which is less than that of the single Pt atoms $(+0.421 e)$. This suggests that upon $\mathrm{H}$ adsorption, each $\mathrm{Pt}$ atom of the $\mathrm{Pt}_{44}$ cluster remains metallic, while the single $\mathrm{Pt}$ atoms on the NGNs become nonmetallic through the donation of electrons to both the substrate and $\mathrm{H}$ atoms. This leads to the unique electronic structure of the single Pt atoms on the NGNs and is expected to be the primary reason of the increased HER activity of the ALD50Pt/NGNs sample.

Our XANES data have experimentally shown that the ALD Pt atoms do in fact have a higher total unoccupied density of $5 d$ states, which agrees with the partial density of states calculation.
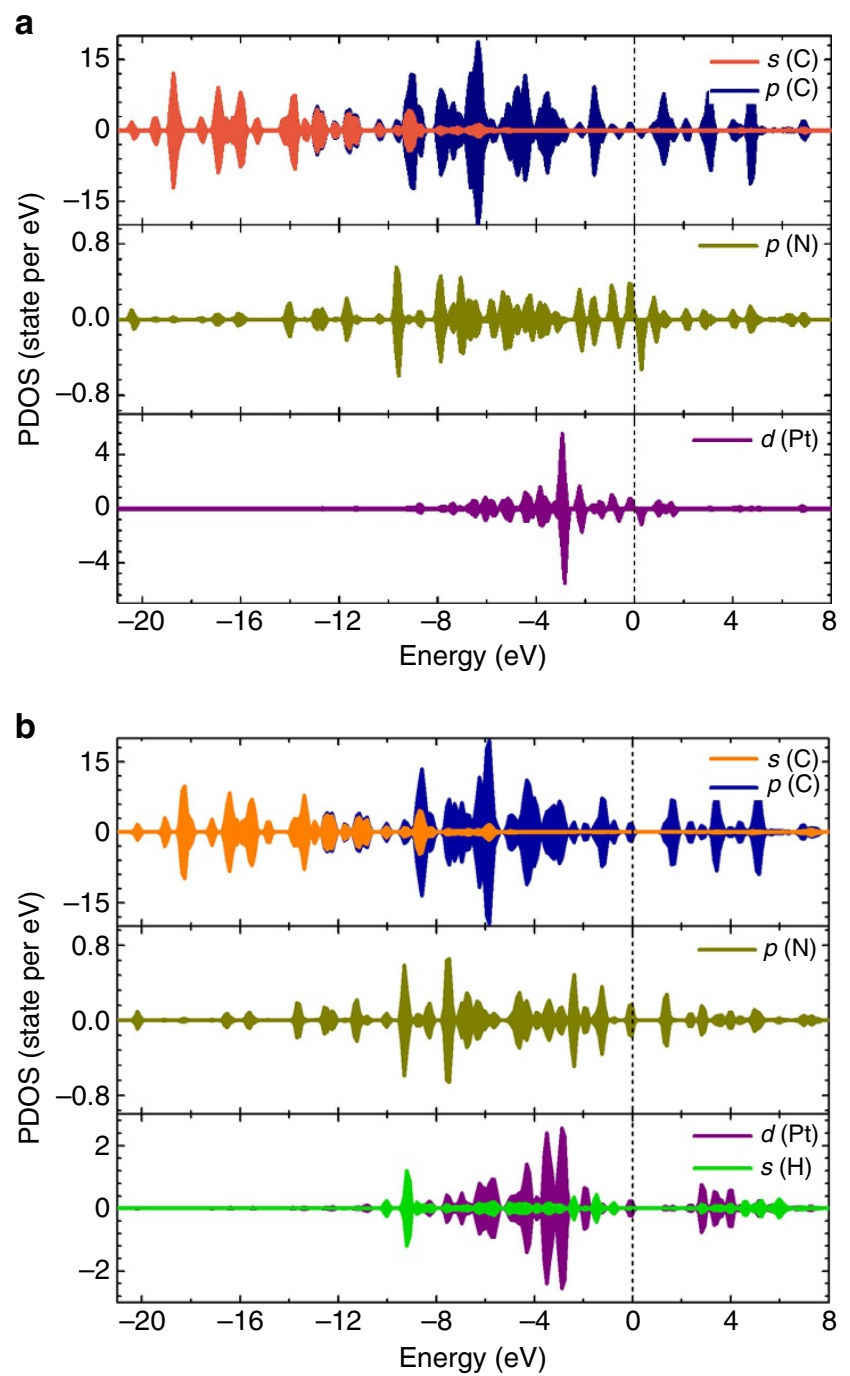

Figure 4 | The electronic structure of a single Pt atom before and after hydrogen adsorption. Partial density of states (PDOS) of (a) non- $\mathrm{H}$ and (b) two $\mathrm{H}$ atoms adsorbed on a single Pt atom of ALDPt/NGNs. The Fermi level is shifted to zero. The upper part of the panel shows the PDOS of graphene, the middle part of the panel gives the PDOS of the $\mathrm{N}$ atom and the lower part of the panel exhibits the PDOS of the $d$ orbital of Pt.

Previous research has suggested that a change in the electronic properties of catalysts will affect the catalytic performance ${ }^{52}$. Thus, we carried out a series of DFT calculations to obtain a fundamental understanding of the unexpectedly high electrocatalytic activity of the single-atom catalysts. For the HER in acidic media, the overall HER pathway $\left(\mathrm{H}^{+}+e^{-} \rightarrow 1 / 2 \mathrm{H}_{2}\right)$ can be divided into two separate pathways comprising either the Volmer-Heyrovsky or the Volmer-Tafel mechanism ${ }^{53,54}$. The first step of both pathways involves the bonding of the hydrogen ion to the catalyst, $\mathrm{H}^{+}+e^{-} \rightarrow \mathrm{H}^{*}$ (Volmer reaction), where $\mathrm{H}^{*}$ indicates an available surface site on the catalyst for hydrogen adsorption. In the next stage, the molecular hydrogen can be released through the Heyrovsky $\left(\mathrm{H}^{+}+e^{-}+\mathrm{H}^{*} \rightarrow \mathrm{H}_{2} \uparrow\right)$ or the Tafel $\left(\mathrm{H}^{\star} \rightarrow 1 / 2 \mathrm{H}_{2}{ }^{\uparrow}\right)$ reaction. Many previous studies ${ }^{55-57}$ have shown that the Tafel mechanism in the electrocatalytic HER is preferred at high $\mathrm{H}$ coverage conditions on both $\mathrm{Pt}$ surfaces and Pt NPs. To verify the proposed HER mechanism, we performed a computational study on the single Pt atom catalysts to gain detailed insights into the HER process. The average $\mathrm{Pt}-\mathrm{H}$ distance for the $\mathrm{H}$ chemisorption configuration was found to be 


\begin{tabular}{|c|c|c|c|c|c|}
\hline & \multirow[t]{2}{*}{$I_{\mathrm{Pt}-\mathrm{N}}(\AA)$} & \multirow[t]{2}{*}{$I_{\mathrm{Pt}-\mathrm{H}}(\AA)$} & \multicolumn{3}{|c|}{ Bader charge (e) } \\
\hline & & & $\mathbf{P t}$ & $\mathbf{N}$ & $\mathbf{H}$ \\
\hline $\begin{array}{l}\text { Hydrogen } \\
\text { adsorption }\end{array}$ & 2.105 & $\begin{array}{l}1.659 \\
1.580\end{array}$ & +0.421 & -1.202 & $\begin{array}{l}-0.073 \\
-0.193\end{array}$ \\
\hline Non-H & 2.309 & - & +0.278 & -1.076 & - \\
\hline
\end{tabular}

Here the bond lengths of Pt-N $\left(I_{\mathrm{Pt}-\mathrm{N}}\right)$ and Pt-H $\left(I_{\mathrm{Pt}-\mathrm{H}}\right)$ are listed. The Bader charge for both Pt, N and $\mathrm{H}$ are shown before and after $\mathrm{H}$ adsorption.

$1.623 \AA$, which was similar with the cases of $\mathrm{H}$ adsorbed on Pt surfaces and nanoclusters ${ }^{58,59}$. It was also determined that the adsorption strengths of both $\mathrm{H}$ and $\mathrm{H}_{2}$ decreased with an increase in the number of adsorbed $\mathrm{H}$ atoms, eventually leading to a minimum value when four $\mathrm{H}$ atoms were adsorbed, as shown in the Supplementary Fig. 17. In the presence of a single $\mathrm{H}$ atom, the most optimal orbital interaction with the Pt catalyst results in the bond formation with the most favourable Pt orbital, $d_{z^{2}}$, with a corresponding adsorption energy of $0.8 \mathrm{eV}$. As the number of interacting $\mathrm{H}$ atoms is increased, their bond formation with $\mathrm{Pt}$ is affected by the electrostatic repulsion between the $\mathrm{H}$ atoms. The $\mathrm{Pt}$ to $\mathrm{H}$ interaction now depends on the number of interacting $\mathrm{H}$ atoms, and the distinct orbitals for bond formation becomes a compromise between the $\mathrm{H}-\mathrm{H}$ electrostatic repulsion and the orbital interaction of $\mathrm{Pt}-\mathrm{H}$. Specifically in the case of two $\mathrm{H}$ atoms, the interacting orbitals between the $\mathrm{H}$ atoms and the $\mathrm{Pt}$ catalyst become the $d_{y z}$ and $d_{x^{2}-y^{2}}$ (Supplementary Fig. 18a), resulting in a corresponding adsorption energy of $0.735 \mathrm{eV}$ per $\mathrm{H}$. Furthermore, when three $\mathrm{H}$ atoms adsorb onto a single $\mathrm{Pt}$ atom, two of the $\mathrm{H}$ atoms automatically form an $\mathrm{H}_{2}$ dimer, due to the fact that the initial two $\mathrm{H}$ atoms have occupied the two empty $5 d$ orbitals of the Pt catalyst. The resulting corresponding adsorption energy for three $\mathrm{H}$ atoms is $0.514 \mathrm{eV}$ per $\mathrm{H}$. Finally, as the number of $\mathrm{H}$ atoms reaches four (Supplementary Fig. 18c), the interaction between the $\mathrm{Pt}$ and $\mathrm{H}$ atoms are through the $d_{y z}$ and $d_{x^{2}-y^{2}}$ orbitals, which can effectively avoid the repulsion between the $\mathrm{H}$ atoms. The corresponding adsorption configuration is one in which an $\mathrm{H}_{2}$ dimer and two isolated $\mathrm{H}$ atoms are formed with an adsorption energy of $0.458 \mathrm{eV}$ per $\mathrm{H}$. The maximum number of adsorbed $\mathrm{H}$ atoms in this situation is four, as Pt no longer has empty $5 d$ orbitals or physical space to allow for the interaction with an additional $\mathrm{H}$ atom.

We further calculated the reaction pathways and activation barriers based on the number of adsorbed $\mathrm{H}$ atoms to verify the proposed HER mechanism on the Pt/NGNs supports, as shown in the Supplementary Fig. 19. The calculated activation barrier was completed for the two models: a low loading of two $\mathrm{H}$ atoms and a high loading of four $\mathrm{H}$ atoms, resulting in energies of 0.664 and $0.571 \mathrm{eV}$, respectively. As previously discussed, the adsorption energy of a $\mathrm{H}$ atom on the single $\mathrm{Pt}$ atom catalyst decreases with an increase in the number of adsorbed $\mathrm{H}$ atoms (Supplementary Fig. 17), which promotes the formation of the $\mathrm{H}_{2}$ molecules. The adsorption of two $\mathrm{H}$ atoms on $\mathrm{Pt}$ (Supplementary Fig. 18a,b) results in a transformation of the hybrid orbital between the $\mathrm{H}$ and $\mathrm{Pt}$ atoms to change from $d_{x^{2}-y^{2}}+d_{y z}$ to $d_{x y}+d_{y z}$ when forming the $\mathrm{H}_{2}$ molecule. This orbital transformation results in the calculated energy barrier of $0.664 \mathrm{eV}$. On the other hand, when considering four $\mathrm{H}$ atoms, two reaction models previously outlined must be considered. The first model is the adsorption of two isolated $\mathrm{H}$ atoms and one $\mathrm{H}_{2}$ dimer, which results in the transformation of the hybrid orbital between the $\mathrm{H}$ and $\mathrm{Pt}$ atoms to change from $d_{x^{2}-y^{2}}+d_{y z}$ to $d_{x y}+d_{y z}$ with an energy barrier of $0.571 \mathrm{eV}$. Second, the adsorption of two $\mathrm{H}_{2}$ dimers on $\mathrm{Pt}$ results in a decreased adsorption energy of $0.336 \mathrm{eV}$ per $\mathrm{H}$ in comparison with the four $\mathrm{H}$ atom model, which should further promote the ease of $\mathrm{H}_{2}$ production on the $\mathrm{Pt}$ atom. Importantly, it should be noted that the energy barrier for $\mathrm{H}_{2}$ formation is lower when four $\mathrm{H}$ atoms are present, thus clarifying that the $\mathrm{H}_{2}$ formation on single $\mathrm{Pt}$ atom catalysts is preferred at high $\mathrm{H}$ coverage. Moreover, the calculated activation barriers for both the two $\mathrm{H}$ and four $\mathrm{H}$ atoms models is smaller than that of the conventional Pt $(111)$ surface $(\sim 0.85 \mathrm{eV})^{56,57}$. The decreased activation barrier calculated for the HER of the single Pt atoms on $\mathrm{N}$-doped graphene is consistent with our experimentally observed fast HER kinetics.

For practical applications concerning single-atom catalysts, a high activity and good stability are paramount to ensure a competitive performance is achieved in comparison with conventional NP catalysts. Furthermore, the performance will rely on achieving a high density of single atoms to ensure that the number of active sites is not reduced. To examine this effect, the performance of 50 ALD cycles was compared with 25 cycles. It was found that the current density of the ALD25Pt/NGNs sample was below that of commercial $\mathrm{Pt} / \mathrm{C}$ catalysts, resulting in the lowest current density shown in Supplementary Fig. 20. The low specific activity of the ALD25Pt/NGNs sample may result from a low density of single $\mathrm{Pt}$ atoms/clusters (Pt loading of $0.19 \%$ ) on the $\mathrm{N}$-doped graphene. The low Pt density could be an effect of the low cycle number and nucleation delay ${ }^{60}$ in the first few ALD cycles.

In conclusion, we fabricated novel Pt catalysts supported by NGNs for the HER using the ALD technique. The size of the Pt catalysts ranged from single atoms, sub-nanometre clusters, to NPs, which were precisely controlled by adjusting the number of ALD cycles. Single Pt atoms and clusters showed exceptionally high activity and stability as HER catalysts compared with commercial $\mathrm{Pt} / \mathrm{C}$ catalysts. The remarkable performance of the single $\mathrm{Pt}$ atoms and clusters arise from their small size and the unique electronic structure originating from of the adsorption of the single $\mathrm{Pt}$ atoms on the $\mathrm{N}$-doped graphene, as confirmed by XANES and DFT analysis. Our work provides a promising approach for the design of highly active and stable nextgeneration catalysts based on single $\mathrm{Pt}$ atoms and clusters, which have a great potential to reduce the high cost of industrial commercial noble-metal catalysts.

\section{Methods}

Synthesis of GNs and NGNs. Graphite oxide was first obtained by a modified Hummers method previously reported by our group ${ }^{61,62}$. The received graphite oxide was then rapidly exfoliated via a thermal treatment at $1,050^{\circ} \mathrm{C}$ under $\mathrm{Ar}$ atmosphere, yielding the product of GNs. NGNs were prepared by post-heating the graphene under high purity ammonia mixed with $\mathrm{Ar}$ at $900^{\circ} \mathrm{C}$ for $10 \mathrm{~min}$.

ALD synthesis of Pt on NGNs. Pt was deposited on the NGNs by ALD (Savannah 100, Cambridge Nanotechnology Inc., USA) using $\mathrm{MeCpPtMe}_{3}$ and $\mathrm{O}_{2}$ as precursors and a procedure similar to one previously reported ${ }^{19}$. High-purity $\mathrm{N}_{2}$ (99.9995\%) was used as both a purging gas and carrier gas. The powder NGNs or GNs were placed in a container inside the ALD reactor chamber. The deposition temperature was $250^{\circ} \mathrm{C}$, while the container for $\mathrm{MeCpPtMe}_{3}$ was kept at $65^{\circ} \mathrm{C}$ to provide a steady-state flux of $\mathrm{MeCpPtMe}_{3}$ to the reactor. Gas lines were held at $100^{\circ} \mathrm{C}$ to avoid precursor condensation. For each ALD cycle, $1 \mathrm{~s}$ of the

$\mathrm{MeCpPtMe}_{3}$ pulse and $5 \mathrm{~s}$ of the $\mathrm{O}_{2}$ pulse were separated by a $20 \mathrm{~s} \mathrm{~N}_{2}$ purge. The size, density and distribution of the Pt catalysts on the NGNs or GNs were precisely controlled by adjusting the number of ALD cycles.

Physical characterization. The ADF STEM images were acquired using an FEI Titan 80-300 Cubed TEM equipped with a monochromator, hexapole-based aberration corrector (Corrected Electron Optical Systems GmbH) in both the probe and imaging lenses, and a high-brightness gun (XFEG) operated with an $80 \mathrm{kV}$ accelerating voltage. High-resolution transmission electron microscopy was performed using an FEI 80-300 Cryo-Twin TEM with a Schottky field emission gun under negative $\mathrm{C}_{\mathrm{s}}$ imaging conditions using a hexapole-based aberration 
corrector in the imaging lens and the electron source operated at $300 \mathrm{kV}$ accelerating voltage. Samples were baked under vacuum at $100^{\circ} \mathrm{C}$ before imaging to prevent beam contamination.

X-ray absorption spectroscopy. XANES measurements of the $\mathrm{Pt}_{\mathrm{L}}$-edge and the $\mathrm{Pt}_{2}$-edge were conducted on the 06ID superconducting wiggler sourced hard $\mathrm{X}$-ray microanalysis beamline at the Canadian Light Source. Each sample spectra were collected in fluorescence yield using a solid-state detector, while the high-purity Pt metal foil spectra were collected in transmission mode for comparison and monochromatic energy calibration.

WL intensity analysis was conducted based on previous research ${ }^{38,40}$. In this method, the $\mathrm{Pt}_{3}$-edge WL intensity was obtained by subtracting the $\mathrm{Pt}_{3}$-edge XANES from the corresponding XANES of Au. The area under the difference curve was integrated between the two vertical bars, and $\Delta A_{3}$ and $\Delta A_{2}$ were calculated using the following expressions:

$$
\begin{aligned}
\Delta A_{3} & =\int \mu(\mathrm{Pt})_{\mathrm{L}_{3} \mathrm{WL}}-\mu(\mathrm{Au})_{\mathrm{L}_{3} \mathrm{WL}} \\
\Delta A_{2} & =\int \mu(\mathrm{Pt})_{\mathrm{L}_{2} \mathrm{WL}}-\mu(\mathrm{Au})_{\mathrm{L}_{2} \mathrm{WL}}
\end{aligned}
$$

According to Sham et $a l .{ }^{40}$, these values are related to the following theoretical expressions:

$$
\begin{gathered}
\Delta A_{3}=C_{0} N_{0} E_{3}\left(R_{d}^{2 p_{2 / 3}}\right)^{2}\left[\frac{6 h_{5 / 2}+h_{3 / 2}}{15}\right] \\
\Delta \mathrm{A}_{2}=C_{0} N_{0} E_{2}\left(R_{d}^{2 p_{1 / 2}}\right)^{2}\left(\frac{1}{3} h_{3 / 2}\right)
\end{gathered}
$$

where $C_{0}=4 \pi r^{2} \alpha / 3$ ( $\alpha$ is the fine structure constant), $N_{0}$ is the density of Pt atoms, $h_{j}$ is the $5 d$ hole counts, $R$ is the radial transition matrix element, and $E_{2}$ and $E_{3}$ are the corresponding edge thresholds $\left(E_{\mathrm{o}}\right)$ for the $\mathrm{L}_{2^{-}}$and $\mathrm{L}_{3}$-edges, respectively. By assuming that the $R$ terms are similar for both edges

$$
C=C_{0} N_{0} R^{2}
$$

and with this approximation

$$
\begin{gathered}
h_{\frac{5}{2}}=\frac{1}{2 C}\left[5 \frac{E_{2}}{E_{3}} \Delta A_{3}-\Delta A_{2}\right] \\
h_{3 / 2}=\left[\frac{3 \Delta A_{2}}{C}\right]
\end{gathered}
$$

The $C$ value for these equations was previously derived for the Pt metal as $7.484 \times 10^{4} \mathrm{~cm}^{-1}$ (ref. 63).

Electrochemical characterization. A three-compartment cell was used for the electrochemical measurements with a glassy carbon rotating-disk electrode (Pine Instruments) as the working electrode. $\mathrm{Hg} / \mathrm{Hg}_{2} \mathrm{SO}_{4}$ electrode and a Pt wire were used as the reference and the counter electrode, respectively. The potentials presented in this study are referred with respect to RHE.

The catalyst dispersions were prepared by mixing $3 \mathrm{mg}$ of catalyst in a $2 \mathrm{ml}$ aqueous solution containing $1 \mathrm{ml}$ of isopropyl alcohol and $30 \mu \mathrm{l}$ of $5 \mathrm{wt} \%$ Nafion solution. Following the solution preparation, the mixture was ultrasonicated for $30 \mathrm{~min}$. Next, the working electrode was created by transferring $10 \mu \mathrm{l}$ of the aqueous catalyst dispersion onto the glassy carbon rotating disk electrode $\left(0.196 \mathrm{~cm}^{2}\right)$. The working electrode was rotated at 1,600 r.p.m. to remove the $\mathrm{H}_{2}$ gas bubbles formed at the catalyst surface.

Computational methods. Our calculations are performed based on DFT calculations, as implemented in the Vienna ab initio package ${ }^{64,65}$. The general gradient approximation of Perdew-Burke-Ernzerhof is adopted for the exchange-correlation functional ${ }^{66}$. Moreover, the electron wave functions were expanded by a plane wave cutoff of $400 \mathrm{eV}$. The $(5 \times 5 \times 1)$ supercell $\mathrm{N}$-doped graphene contains $48 \mathrm{C}$ atoms and $1 \mathrm{~N}$ atom was constructed by a periodic boundary condition, and the vacuum layers were set to be larger than $20 \AA$ to avoid periodic interaction. Reciprocal space was performed by the Monkhorst-Pack special $k$-point scheme with $5 \times 5 \times 1$ grid meshes for structure relaxation for the $\mathrm{Pt}$ adsorbed on $\mathrm{N}$-doped graphene. Atomic relaxation was performed until the total energy variation was smaller than $10^{-6} \mathrm{eV}$ and all forces on each atom were $<0.01 \mathrm{eV}^{-1}$. The van der Waals density functional ${ }^{67,68}$ approach was used to evaluate the effect of the van der Waals interaction ${ }^{6}$.

We determined the free energy barrier for the HER on the Pt adsorbed on $\mathrm{N}$-doped graphene according to the Volmer-Tafel route using the climb image nudged elastic band method ${ }^{69}$. A set of images $(N=9)$ is uniformly distributed along the reaction path connecting the initial and final states optimized in our simulation. To ensure the continuity of the reaction path, the images are coupled with elastic forces, and each intermediate state was fully relaxed in the hyperspace perpendicular to the reaction coordinate. The Bader charge analysis ${ }^{70}$ was performed to quantitatively estimate the amount of charge transfer between the adsorbed $\mathrm{Pt}($ or $\mathrm{H})$ and the $\mathrm{N}$-doped graphene.

Date availability. The data that support the findings of this study are available from the corresponding authors on request.

\section{References}

1. Tong, W., West, A., Cheung, K., Yu, K.-M. \& Tsang, S. C. E. Dramatic effects of gallium promotion on methanol steam reforming $\mathrm{Cu}-\mathrm{ZnO}$ catalyst for hydrogen production: formation of $5 \AA$ copper clusters from $\mathrm{Cu}-\mathrm{ZnGaO}_{\mathrm{x}}$. ACS Catal. 3, 1231-1244 (2013).

2. Crabtree, G. W., Dresselhaus, M. S. \& Buchanan, M. V. The hydrogen economy. Phys. Today 57, 39-44 (2004).

3. Yu, K. M. K. et al. Non-syngas direct steam reforming of methanol to hydrogen and carbon dioxide at low temperature. Nat. Commun. 3, 1230 (2012).

4. Chorkendorff, I. \& Niemantsverdriet, J. W. Concepts of Modern Catalysis and Kinetics (Wiley-VCH, 2003).

5. Subbaraman, R. et al. Enhancing hydrogen evolution activity in water splitting by tailoring $\mathrm{Li}^{+}-\mathrm{Ni}(\mathrm{OH})_{2}-\mathrm{Pt}$ interfaces. Science 334, 1256-1260 (2011).

6. Subbaraman, R. et al. Trends in activity for the water electrolyser reactions on 3d M(Ni,Co,Fe,Mn) hydr(oxy)oxide catalysts. Nat. Mater. 11, 550-557 (2012).

7. Yin, H. J. et al. Ultrathin platinum nanowires grown on single-layered nickel hydroxide with high hydrogen evolution activity. Nat. Commun. 6, 6430 (2015).

8. Merki, D. \& Hu, X. L. Recent developments of molybdenum and tungsten sulfides as hydrogen evolution catalysts. Energ. Environ. Sci. 4, 3878-3888 (2011).

9. Chen, S., Duan, J., Tang, Y., Jin, B. \& Qiao, S. Molybdenum sulfide clustersnitrogen-doped graphene hybrid hydrogel film as an efficient threedimensional hydrogen evolution electrocatalyst. Nano Energy 11, 11-18 (2015).

10. Voiry, D. et al. Enhanced catalytic activity in strained chemically exfoliated $\mathrm{WS}_{2}$ nanosheets for hydrogen evolution. Nat. Mater. 12, 850-855 (2013).

11. Gao, M. R. et al. An efficient molybdenum disulfide/cobalt diselenide hybrid catalyst for electrochemical hydrogen generation. Nat. Commun. 6, 5982 (2015).

12. Zheng, Y. et al. Hydrogen evolution by a metal-free electrocatalyst. Nat. Commun. 5, 3783 (2014).

13. Duan, J., Chen, S., Jaroniec, M. \& Qiao, S. Porous $\mathrm{C}_{3} \mathrm{~N}_{4}$ nanolayers@Ngraphene films as catalyst electrodes for highly efficient hydrogen evolution. ACS Nano 9, 931-940 (2015).

14. Liu, J. et al. Metal-free efficient photocatalyst for stable visible water splitting via a two-electron pathway. Science 347, 970-974 (2015).

15. Stephens, I. E. L. \& Chorkendorff, I. Minimizing the use of platinum in hydrogen-evolving electrodes. Angew. Chem. Int. Ed. 50, 1476-1477 (2011).

16. Esposito, D. V. et al. Low-cost hydrogen-evolution catalysts based on monolayer platinum on tungsten monocarbide substrates. Angew. Chem. Int. Ed. 49, 9859-9862 (2010).

17. Yang, X. F. et al. Single-atom catalysts: a new frontier in heterogeneous catalysis. Acc. Chem. Res. 46, 1740-1748 (2013).

18. Qiao, B. T. et al. Single-atom catalysis of $\mathrm{CO}$ oxidation using $\mathrm{Pt}_{1} / \mathrm{FeO}_{\mathrm{x}} \cdot$ Nat. Chem. 3, 634-641 (2011).

19. Sun, S. H. et al. Single-atom catalysis using Pt/graphene achieved through atomic layer deposition. Sci. Rep. 3, 1775 (2013).

20. Uzun, A., Ortalan, V., Hao, Y. L., Browning, N. D. \& Gates, B. C. Nanoclusters of gold on a high-area support: almost uniform nanoclusters imaged by scanning transmission electron microscopy. ACS Nano 3, 3691-3695 (2009).

21. Mackus, A. J. M., Verheijen, M. A., Leick, N., Bol, A. A. \& Kessels, W. M. M. Influence of oxygen exposure on the nucleation of platinum atomic layer deposition: consequences for film growth, nanopatterning, and nanoparticle synthesis. Chem. Mater. 25, 1905-1911 (2013).

22. Yang, M. et al. Catalytically active $\mathrm{Au}-\mathrm{O}(\mathrm{OH})_{\mathrm{x}}$-species stabilized by alkali ions on zeolites and mesoporous oxides. Science 346, 1498-1501 (2014).

23. Zhang, X. F. et al. Catalytically active single-atom niobium in graphitic layers. Nat. Commun. 4, 1924 (2013).

24. Stambula, S. et al. Chemical structure of nitrogen-doped graphene with single platinum atoms and atomic clusters as a platform for the PEMFC electrode. J. Phys. Chem. C 118, 3890-3900 (2014).

25. George, S. M. Atomic layer deposition: an overview. Chem. Rev. 110, 111-131 (2010).

26. Marichy, C., Bechelany, M. \& Pinna, N. Atomic layer deposition of nanostructured materials for energy and environmental applications. $A d v$. Mater. 24, 1017-1032 (2012).

27. Puurunen, R. L. Surface chemistry of atomic layer deposition: A case study for the trimethylaluminum/water process. J. Appl. Phys. 97, 121301 (2005).

28. Lu, J., Aydin, C., Browning, N. D. \& Gates, B. C. Imaging isolated gold atom catalytic sites in zeolite NaY. Angew. Chem. Int. Ed. 51, 5842-5846 (2012).

29. Wang, S. W. et al. Dopants adsorbed as single atoms prevent degradation of catalysts. Nat. Mater. 3, 274-274 (2004). 
30. Cheng, N. C. et al. Atomic scale enhancement of metal-support interactions between $\mathrm{Pt}$ and $\mathrm{ZrC}$ for highly stable electrocatalysts. Energ. Environ. Sci. 8, 1450-1455 (2015).

31. Conway, B. E. \& Tilak, B. V. Interfacial processes involving electrocatalytic evolution and oxidation of $\mathrm{H}_{2}$, and the role of chemisorbed $\mathrm{H}$. Electrochim. Acta 47, 3571-3594 (2002).

32. Zhang, S. R. et al. Catalysis on singly dispersed bimetallic sites. Nat. Commun. 6, 7938 (2015).

33. Liu, Y. \& Mustain, W. E. Evaluation of tungsten carbide as the electrocatalyst support for platinum hydrogen evolution/oxidation catalysts. Int. J. Hydrogen Energ. 37, 8929-8938 (2012).

34. Jiang, Z. Z., Wang, Z. B., Chu, Y. Y., Gu, D. M. \& Yin, G. P. Ultrahigh stable carbon riveted $\mathrm{Pt} / \mathrm{TiO}_{2}-\mathrm{C}$ catalyst prepared by in situ carbonized glucose for proton exchange membrane fuel cell. Energ. Environ. Sci. 4, 728-735 (2011).

35. Xia, B. Y. et al. Sandwich-structured $\mathrm{TiO}_{2}$-Pt-graphene ternary hybrid electrocatalysts with high efficiency and stability. J. Mater. Chem. 22, 16499-16505 (2012).

36. Shao-Horn, Y. et al. Instability of supported platinum nanoparticles in low-temperature fuel cells. Top. Catal. 46, 285-305 (2007).

37. Cheng, N. A. C., Mu, S. C., Pan, M. \& Edwards, P. P. Improved lifetime of PEM fuel cell catalysts through polymer stabilization. Electrochem. Commun. 11, 1610-1614 (2009).

38. Banis, M. N. et al. $\mathrm{TiSi}_{2} \mathrm{O}_{\mathrm{x}}$ coated $\mathrm{N}$-doped carbon nanotubes as Pt catalyst support for the oxygen reduction reaction in PEMFCs. J. Phys. Chem. C 117, 15457-15467 (2013).

39. Ho, V. T. T., Pan, C.-J., Rick, J., Su, W.-N. \& Hwang, B.-J. Nanostructured $\mathrm{Ti}_{0.7} \mathrm{Mo}_{0.3} \mathrm{O}_{2}$ support enhances electron transfer to Pt: high-performance catalyst for oxygen reduction reaction. J. Am. Chem. Soc. 133, 11716-11724 (2011).

40. Sham, T. K., Naftel, S. J. \& Coulthard, I. $\mathrm{M}_{3,2}$-edge X-ray absorption near-edge structure spectroscopy: an alternative probe to the $\mathrm{L}_{3,2}$-edge near-edge structure for the unoccupied densities of d states of $5 \mathrm{~d}$ metals. J. Appl. Phys. 79, 7134-7138 (1996).

41. Mansour, A. N., Cook, J. W. \& Sayers, D. E. Quantitative technique for the determination of the number of unoccupied d-electron states in a platinum catalyst using the $\mathrm{L}_{2,3} \mathrm{X}$-ray absorption-edge spectra. J. Phys. Chem. 88, 2330-2334 (1984).

42. Hu, P. P. et al. Electronic Metal-support interactions in single-atom catalysts. Angew. Chem. Int. Ed. 53, 3418-3421 (2014).

43. Qiao, B. et al. Ultrastable single-atom gold catalysts with strong covalent metal-support interaction (CMSI). Nano Res. 8, 2913-2924 (2015).

44. Kondo, T., Suzuki, T. \& Nakamura, J. Nitrogen doping of graphite for enhancement of durability of supported platinum clusters. J. Phys. Chem. Lett. 2, 577-580 (2011)

45. Chen, Y. G. et al. Enhanced stability of Pt electrocatalysts by nitrogen doping in CNTs for PEM fuel cells. Electrochem. Commun. 11, 2071-2076 (2009).

46. Bulushev, D. A. et al. Single atoms of Pt-group metals stabilized by N-doped carbon nanofibers for efficient hydrogen production from formic acid. ACS Catal. 6, 3442-3451 (2016).

47. Cheng, N. et al. Extremely stable platinum nanoparticles encapsulated in a zirconia nanocage by area-selective atomic layer deposition for the oxygen reduction reaction. Adv. Mater. 27, 277-281 (2015).

48. Wu, J. F. et al. A review of PEM fuel cell durability: degradation mechanisms and mitigation strategies. J. Power Sources 184, 104-119 (2008).

49. Ghosh, T. K. \& Nair, N. N. Rh1 $/ \gamma-\mathrm{Al}_{2} \mathrm{O}_{3}$ single-atom catalysis of $\mathrm{O}_{2}$ activation and $\mathrm{CO}$ oxidation: mechanism, effects of hydration, oxidation state, and cluster size. ChemCatChem 5, 1811-1821 (2013).

50. Hackett, S. F. J. et al. High-activity, single-site mesoporous $\mathrm{Pd} / \mathrm{Al}_{2} \mathrm{O}_{3}$ catalysts for selective aerobic oxidation of allylic alcohols. Angew. Chem. Int. Ed. 119, 8747-8750 (2007)

51. Zhang, X., Shi, H. \& Xu, B. Q. Catalysis by gold: isolated surface $\mathrm{Au}^{3+}$ Ions are active sites for selective hydrogenation of 1, 3-butadiene over $\mathrm{Au} / \mathrm{ZrO}_{2}$ catalysts. Angew. Chem. Int. Ed. 44, 7132-7135 (2005).

52. Norskov, J. K., Bligaard, T., Rossmeisl, J. \& Christensen, C. H. Towards the computational design of solid catalysts. Nat. Chem. 1, 37-46 (2009).

53. Conway, B. \& Tilak, B. Interfacial processes involving electrocatalytic evolution and oxidation of $\mathrm{H}_{2}$, and the role of chemisorbed $\mathrm{H}$. Electrochim. Acta 47, 3571-3594 (2002).

54. Parsons, R. The rate of electrolytic hydrogen evolution and the heat of adsorption of hydrogen. Trans. Faraday Soc. 54, 1053-1063 (1958).

55. Ge, M., Fang, X., Rong, J. \& Zhou, C. Review of porous silicon preparation and its application for lithium-ion battery anodes. Nanotechnology 24, 422001 (2013).

56. Wei, G.-F. \& Liu, Z.-P. Restructuring and hydrogen evolution on Pt nanoparticle. Chem. Sci. 6, 1485-1490 (2015).

57. Skúlason, E. et al. Modeling the electrochemical hydrogen oxidation and evolution reactions on the basis of density functional theory calculations. J. Phys. Chem. C 114, 18182-18197 (2010).

58. Okamoto, Y. Comparison of hydrogen atom adsorption on Pt clusters with that on Pt surfaces: a study from density-functional calculations. Chem. Phys. Lett. 429, 209-213 (2006).
59. Papoian, G., Nørskov, J. K. \& Hoffmann, R. A comparative theoretical study of the hydrogen, methyl, and ethyl chemisorption on the Pt (111) surface. J. Am. Chem. Soc. 122, 4129-4144 (2000).

60. Cheng, N., Shao, Y., Liu, J. \& Sun, X. Electrocatalysts by atomic layer deposition for fuel cell applications. Nano Energy. http://dx.doi.org/10.1016/ j.nanoen.2016.01.016 (2016).

61. Geng, D. et al. High oxygen-reduction activity and durability of nitrogen-doped graphene. Energ. Environ. Sci. 4, 760-764 (2011).

62. Kibsgaard, J., Gorlin, Y., Chen, Z. \& Jaramillo, T. F. Meso-structured platinum thin films: active and stable electrocatalysts for the oxygen reduction reaction. J. Am. Chem. Soc. 134, 7758-7765 (2012).

63. Mattheiss, L. F. \& Dietz, R. E. Relativistic tight-binding calculation of core-valence transitions in Pt and Au. Phys. Rev. B 22, 1663-1676 (1980).

64. Kresse, G. \& Furthmüller, J. Efficiency of ab-initio total energy calculations for metals and semiconductors using a plane-wave basis set. Comput. Mater. Sci. 6, 15-50 (1996).

65. Kresse, G. \& Furthmüller, J. Efficient iterative schemes for ab initio total-energy calculations using a plane-wave basis set. Phys. Rev. B 54, 11169 (1996).

66. Perdew, J. P. et al. Atoms, molecules, solids, and surfaces: applications of the generalized gradient approximation for exchange and correlation. Phys. Rev. B 46, 6671 (1992).

67. Dion, M., Rydberg, H., Schroder, E., Langreth, D. C. \& Lundqvist, B. I. Van der Waals density functional for general geometries. Phys. Rev. Lett. 92, 246401 (2004).

68. Klimes, J., Bowler, D. R. \& Michaelides, A. Van der Waals density functionals applied to solids. Phys. Rev. B 83, 195131 (2011).

69. Henkelman, G., Uberuaga, B. P. \& Jónsson, H. A climbing image nudged elastic band method for finding saddle points and minimum energy paths. J. Chem. Phys. 113, 9901-9904 (2000).

70. Henkelman, G., Arnaldsson, A. \& Jónsson, H. A fast and robust algorithm for Bader decomposition of charge density. Comput. Mater. Sci. 36, 354-360 (2006).

\section{Acknowledgements}

This research was supported by Catalysis Research for Polymer Electrolyte Fuel Cells (CaRPE-FC), Natural Sciences and Engineering Research Council of Canada (NSERC), Canadian Light Source (CLS), Canada Research Chair (CRC) Program, Canada Foundation for Innovation (CFI), Ontario Research Fund (ORF), Automotive Partnership of Canada (APC) and the University of Western Ontario. The electron microscopy presented here was completed at the Canadian Center for Electron Microscopy, a facility supported by the Canada Foundation for Innovation, NSERC and McMaster University. L.L.M. was supported by the National Natural Science Foundation of China (NSFC) (grant no. 51572016 and U1530401). The computation supports from Tianhe-JK at the Beijing Computational Science Research Center (CSRC) and the Special Program for Applied Research on Super Computation of the NSFC-Guangdong Joint Fund (the second phase) are also acknowledged.

\section{Author contributions}

N.C. designed the project and performed the catalyst preparation, characterizations and catalytic tests; S.S. conducted the STEM image acquisition and N.C. conducted STEM image analyses; M.N.B. carried out measurements and data analyses of EXAFS;

J.L. helped with the ALD process; A.R., R.L. and B.X. helped to analyse the data; D.W. and L.-M.L. performed the DFT calculations; X.S., G.A.B. and T.-K.S. proposed, planned, designed and supervised the project. All authors reviewed the manuscript.

\section{Additional information}

Supplementary Information accompanies this paper at http://www.nature.com/ naturecommunications

Competing financial interests: The authors declare no competing financial interests.

Reprints and permission information is available online at http://npg.nature.com/ reprintsandpermissions/

How to cite this article: Cheng, N. et al. Platinum single-atom and cluster catalysis of the hydrogen evolution reaction. Nat. Commun. 7, 13638 doi: 10.1038/ncomms13638 (2016)

Publisher's note: Springer Nature remains neutral with regard to jurisdictional claims in published maps and institutional affiliations.

This work is licensed under a Creative Commons Attribution 4.0 International License. The images or other third party material in this article are included in the article's Creative Commons license, unless indicated otherwise in the credit line; if the material is not included under the Creative Commons license, users will need to obtain permission from the license holder to reproduce the material. To view a copy of this license, visit http://creativecommons.org/licenses/by/4.0/

C) The Author(s) 2016 